\title{
SOBRE LA POSIBILIDAD REAL DE LA FILOSOFIA
}

\section{Consideraciones preliminares}

Una de las más provechosas experiencias que ofrece la lectura meditada de la historia de la filosofía es, sin lugar a dudas, la que consiste en comprobar cómo el quehacer filosófico se caracteriza inequívocamente, en radical diferencia con otros saberes, por su necesidad de reforma y reconstitución, tan íntegra, cada vez que se le acomete -según lo demuestra su propia historia-, que se puede afirmar que la filosofía, si ha de tener algún sentido, vale decir alguna justificación, sólo puede encontrarlo en esa forma radical de su contenido y modo de operar, si es que de veras aspira a subsistir como una manifestación válida del conocimiento a que puede llegar el hombre, y, todavía más, de donde dimana su conflicto, la máxima manifestación válida del saber en general.

Esta última expresión es quizás la que determina en definitiva la suerte de la filosofía, porque la doble pretensión de un saber que implica todo posible saber y del cual aspira a ser la máxima expresión válida posible le señalan ya a la filosofía ciertas dificultades, sin las cuales no podría haber llegado a ser todo lo que ya es; pero que, por otra parte, y por lo mismo, no le permiten, como probablemente jamás se lo permitan, llegar a ser todo lo que no es. Porque en esta esencial paradoja parece venir a consistir la filosofía, a saber: ser lo que no puede y no ser lo que debe.

El itinerario filosófico desde Tales hasta Heidegger nos deja ver a las claras que la filosofía ha sido, de una parte -en contadas ocasiones-, resuelta y dramática expresión de su naturaleza conflictiva, paradójica: éste es el caso de Sócrates, Descartes y Husserl. En los grandes momentos que corresponden a dichos pensadores, la filosofía, a la vez que se ha mostrado al desnudo, dando al aire sus más turbadoras intimidades, vale decir la esencia misma de su contradictibilidad, o sea la paradoja en que consiste su naturaleza; a la vez que ha hecho esto, ha sido el punto de partida de un optimista afán por escapar a toda contradicción, a toda radical imposibilidad, y de ahí la plétora filosófica que subsigue a Sócrates (Platón, Aristóteles, Plotino, todo el filosofar cristiano de la antigüedad y el medievo), como igualmente a Descartes (toda la modernidad) y lo mismo a Husserl, pues basta pensar en la mole impresionante de la filosofía contemporánea. Y es esto lo que, por otra parte, ha sido la filosofía, es decir, la "construcción" entusiasmada y hasta delirante en ocasiones (piénsese, por ejemplo, en Hegel) de toda suerte de imaginables posibilidades de deshacer la imposibilidad en que parece resolverse la filosofía desde sus mismos comienzos. Se diría que los contados y solemnes momentos en que el filosofar [ 292 ] 
cobra plena conciencia de sí mismo, en los que parece dejar de actuar con el automatismo que uno cree advertir, siempre de algún modo, en la mayoría de las elaboraciones filosóficas -algo así como una obsesión de finalidad a toda costa-, que tales contadas y solemnes ocasiones son como una incitación para el comienzo de una carrera que sólo concluye, al cabo de algunos siglos, cuando la actividad filosófica queda exhausta por consecuencia de su infatigable creatividad, y debe entonces volverse otra vez sobre sí misma y preguntar por el valor y el sentido de lo que en el trayecto recorrido ha podido realizar efectivamente. Sin embargo, una duda inicial, como insoslayable cuestión previa, nos sale al paso, para decirnos si, por ventura, también los contados filósofos que han hecho de la filosofía un memento homo se han quedado en esta escueta actitud, o si, por el contrario, ellos no han intentado también fraguar soluciones y dejar como definitivas algunas de aquellas cuestiones por las cuales han debido, en el comienzo, someter a implacable crítica la naturaleza misma de la filosofía. Porque, relativamente en Sócrates, pero sin lugar a dudas en lo que concierne a Descartes y a Husserl, la filosofía ofrece también su contenido positivo, al menos en lo que alude a la formulación de soluciones. Pero, en este caso, si bien es cierto que ningún filósofo ha dejado de darnos su versión de la realidad según él la entiende, en los que, como Sócrates, Descartes y Husserl, hay inicialmente una actitud rigurosamente crítica, también es posible advertir que el contenido de sus meditaciones es como una masa que gira atraída en su movimiento por el punto de partida problemático y problematizante, y que las dificultades que constituyen el comienzo subsisten siempre $y$, por consiguiente, jamás dejan coagular ese contenido especulativo en la forma que es posible advertirlo en otros filósofos. Tal es la diferencia más importante que, a nuestro juicio, cabe encontrar entre Sócrates y el mismo Platón o Aristóteles, como asimismo entre Descartes y Leibniz, o Kant o Hegel; como sucede de igual modo entre Husserl y cualquiera de sus contemporáneos.

La reforma y reconstitución que acontece temporalmente a la filosofía no es, desde luego, algo que le acontezca a ella solamente, sino que, como es sabido, pertenece a la naturaleza misma del proceso del saber en general. Pero la reforma de las ciencias - para hablar con los mismos términos de Husserl- no tiene lugar del mismo modo que en la filosofía, pues mientras en aquéllas toda reforma ha de ser siempre parcial y relativamente condicionada en cada forma de conocimiento a las restantes formas, en la filosofía, por el contrario, la reforma ha de ser siempre total y sin relación alguna con el resto de los saberes, ya que, por el contrario, son éstos los que han de buscar apoyo y justificación en la reforma integral de la filosofía. Y así como una reforma total de la ciencia la invalidaría para siempre, toda reforma parcial de la filosofía no hace sino entorpecer paulatinamente su real posibilidad de desarrollo. Esta es la obra muerta de la actividad filosófica, o su inevitable lastre, que a trechos tiene que ir liberando, si quiere persistir como tal actividad filosófica. 
En consecuencia, la reforma de la filosofía que se va elaborando a partir de un momento de denuncia de su estado crítico, eso es precisamente lo que podemos llamar reformas parciales, sobreañadidos y retoques (la idea platónica y la materia y la forma aristotélicas, como lastre principal a partir de Sócrates; el monismo spinoziano, la mónada de Leibniz, el ocasionalismo de Malebranche, el empirismo inglés a partir de Locke, como consecuencia de Descartes; el existencialismo, la axiología fenomenológica, el empirismo lógico, etc., tras Husserl). Esta dificultad en que va consistiendo la filosofía, en que resulta ella a partir de la espectacular denuncia de su crisis, ya por entonces casi insalvable, está tejida con la urdimbre que proporcionan todos aquellos pensamientos que se sobreañaden al momento solemne de la denuncia de sus males y al análisis espectral que sobreviene de inmediato. Se diría que la posibilidad de que exista la filosofía, a partir del momento susodicho, consiste en la yuxtaposición de imposibilidades, las cuales van lastrando la filosofía con un peso muerto, del que sólo otro momento de singular lucidez puede liberarla... pero sólo para dar comienzo a un nuevo proceso similar a los anteriores, en cuanto se refiere a la imposibilidad misma.

Lo que se acaba de exponer lleva inevitablemente a la siguiente conclusión: que en la filosofía no subsiste, tras el momento de revisión que alguien acomete en la forma que, por ejemplo, lo realiza Descartes, nada válido. Pero ésta no sería, en modo alguno, una consecuencia aceptable, si se la obtiene en la forma usual de generalización. Pues el caso de la filosofía es, en lo que respecta al problema del saber, un caso sui generis, ya que no se trata, entonces, de descubrir, organizar y exponer, tal como han de hacerlo los restantes saberes. Si así fuera, la filosofía sería entonces un saber más, otra forma de saber que añadir al conjunto de los existentes. Pero pertenece a la esencia misma de la filosofía, por una parte, la característica de ser una crítica de todo fundamento, y, por otra, la característica de ser una supresión de toda posible parcialización dol conocimiento. Es decir, que en modo alguno, ni en instante alguno del tiempo, puede la actividad filosófica, si ha de seguir siendo lo que realmente tiene que ser, convertirse en justificadora de una situación dada, como sí ocurre con la ciencia en general. Me refiero, por supuesto, a la verdadera filosofía y no a tanto pretenso sustitutivo de ella, como es de sobra conocido. De donde la inevitable pluralidad y disparidad de criterios sobre, por ejemplo, la noción de sustancia, o de causa, o de libertad, o de belleza, etc. Mientras que la ciencia, salvo discrepancias que son más bien de detalle, se asienta sobre el sólido basamento de concepciones que sólo experimentan bruscos cambios muy tardíamente, y aun esto mismo en forma que resulta atenuada por cierta relatividad en el tránsito de una idea de la cuestión a otra. Y es que la filosofía está en todas partes y a la vez no se encuentra en ninguna. No podemos decir que la filosofía pertenece al sector de la matemática, o de la física, o de la historia, o el arte; pero ¿qué duda cabe acerca de que, en cierto modo, no puede 
haber filosofía si no se la implica en todos esos saberes? Y advierto que no me estoy refiriendo a esa manipulación "regional", como diría Husserl, que se denomina filosofía de la matemática, o filosofía de la historia, o del arte, etc. No. Sino que por cuanto todo saber es referencia a una manifestación de la realidad, ninguno puede, en consecuencia, escapar a su implicación en la filosofía. Pero es que, extendiendo todavía más la cuestión, resulta que, con toda propiedad, no cabe asignar a la filosofía ni siquiera aquellos sectores como el de la ontología, la teoría del objeto o la gnoseología, donde aún parece que puede ser ubicada. Pues en cuanto cualquiera de esos saberes se constituye con cierta precisión temática y deja ver cierto contorno más o menos definido, comienza a escapar de la filosofía como posible asiento real y efectivo de ésta. $O$ sea, que en cuanto un sector del conocimiento en general deja de ser motivo de "escándalo", dado que ya posee un determinado objeto específico y sus finalidades consiguientes, se pierde irremisiblemente para la filosofía como posible fundamento de esta actividad. La filosofía parece, pues, no estar en ninguna parte, sino más bien ser algo. La pregunta que sobreviene entonces, y que parece que no es posible soslayar en modo alguno, es la siguiente: ¿cómo puede la filosofía no estar en ninguna parte, $y$, sin embargo, ser algo? Para responder a esta pregunta, es preciso referirse antes a otra peculiaridad de la filosofía como es la del sujeto filosofante.

\section{El problema del "sujeto filosofante"}

Creo que no resulta en modo alguno exagerado afirmar que la causa directa y deliberada de la filosofía es quién la hace. Digo que no hay exageración en esto, porque así, de buenas a primeras, parece que también debe haber siempre un alguien responsable de todo saber, no importa el que sea. Pero al reflexionar de este modo, corremos el peligro de hablar con demasiada ligereza, pues si bien es cierto que jamás puede faltar un sujeto cognoscente a quien interesa saber el algo y los porqués de lo que conoce, no es menos cierto que, en apreciable medida, cualquiera de esos saberes, excepto el filosófico, constituye una típica forma de reacción ante lo que está a la mano, un tanto a la zuhandene Welt, que dice Heidegger. Mientras que la filosofía es siempre escándalo, un buscar los tres pies al gato, o empeñarse tal vez, según la despiadada ironía volteriana, en encontrar ese felino, que no existe, en la oscuridad de un aposento. Como es de sobra sabido, la filosofía, siempre que lo es de veras, constituye una cuestión personalísima del filósofo, a tal punto, que de la actitud filosofica real o supuesta que adopte quien filosofa depende siempre que haya o no haya efectivamente eso que puede ser llamado la filosofía.

Pero -y aquí viene a su punto la cuestión-, si el filósofo se propone realmente saber, ¿qué saber es el que aspira a alcanzar con su actividad? Porque 
la experiencia en que consiste la dilatada trayectoria histórica del filosofar demuestra, sin lugar a dudas, que la filosofía no se puede justificar con el simple saber como comprobar, aun cuando esta comprobación implique todos los procesos de conocimiento posibles, hasta los de más subido nivel. No es el contenido, ni su convincente explicación, ni las comprobaciones más satisfactorias lo que puede justificar la existencia de la filosofía, como sí es el caso de la ciencia y en general de toda otra forma de conocimiento. La filosofía no puede aspirar a un saber que sea meramente informativo o explicativo, o de justificación de una determinada clase de realidad, con el propósito de obtener para dicho saber un rango ontológico y epistemologico que le capacite para convivir con otras formas del saber ya organizado. Por esto es que la física, o la psicología, o la sociología se incorporan históricamente, vale decir en un momento determinado, al conjunto de las ciencias ya existentes, a causa precisamente de que han alcanzado ya la delimitación mínima de sus respectivos contenidos y la justificación de su convivencia como saberes organizados. Mientras que el filosofar no ha alcanzado jamás, ni tiene sentido que lo alcance, un redondeamiento de su corpus idearum, que le habilite para la pacífica convivencia junto a las demás ciencias, en respetuosa tangencia con ellas y preocupada, sobre todo, por desarrollar sus propias posibilidades. La peripecia del filósofo importa la de su propia personalidad como tal y supone rigurosamente ese saber del no saber con el cual -perfeccionando la convicción pitagórica ${ }^{1}$ el viejo sátiro ateniense comprometió para siempre al filósofo con su quehacer. Esa docta ignorancia que obliga al filósofo a partir siempre de una comprobación insoslayable como es la que consiste en advertir que la sabiduría no es cosa de más o menos cantidad de conocimiento, ni de dominio o pericia en su manejo, sino, por el contrario, resulta siempre implacable renuncia a todo saber, tal como, hasta su muerte, defiende y predica Sócrates en las calles y plazas de Atenas. Renuncia al saber que aparece maravillosamente expresada en la ironía socrática. En efecto, Sócrates no sólo no sabe nada, cosa de la cual está plenamente convencido, sino que, además, y sobre todo, está convencido de que jamás podrá saber algo. Pero dpor qué no puede llegar a saber nada? No porque se lo impida un saber que, en formas múltiples y más o menos precisas, está ante él, en torno suyo; ni mucho menos por subjetiva incapacidad de aprehender conocimientos. ${ }^{2}$ No se trata de nada de esto, sino de algo de

1 "Raros esse quosdam, qui ceteris omnibus pro nihilo habitis rerum naturam studiose intuerentur: hos se apellare sapientiae studiosos (id est enim philosophos)." Cicerón, Cuestiones tusculanas, $\mathrm{V}, 3$, refiere que éstas fueron las palabras de Pitágoras a León, el tirano de Fliunte, quien indagó con él acerca de la verdadera naturaleza del filósofo.

2 "Lo que casi seguramente constituye una certeza es, varones atenienses, que real y verdaderamente sólo Dios es sabio (ó Đeòs бọò silval), y que el oráculo sólo pretende expresar que 'muy poco o nada es lo que vale la sabidura humana'. Y no me parece que quiera decir que 'Sócrates es sabio', sino servirse tan sólo de mi nombre como de paradigma, cual si dijera: 'será el más sabio de vosotros, oh hombres, aquel que, como lo hace 
naturaleza radicalmente diferente, tan diferente, que en ello va implicado el destino del filosofar. Por eso la gran hazaña socrática es, en mi concepto, la utilización de la ironía, ese formidable instrumento que sirve admirablemente para calar hasta las más oscuras profundidades del espíritu humano y llegar a la conclusión de que, si algo constituye realmente la sabiduría, es precisamente ese austero y melancólico estado por el cual el hombre comprende que hay, en efecto, un saber que es en esencia aspiración a justificar la propia existencia del hombre, y que esta justificación no puede provenir de ninguna realidad externa y ajena a lo humano, sino que, muy por el contrario, ha de hallarla el hombre en sí mismo. De donde esa conversión anhelada por el filósofo, que se manifiesta en la ironía socrática como expresión de radical desconfianza a todo lo exterior, en el interiorismo agustiniano, en el solipsismo en que se funda la subjetividad filosofante de Cartesius y en la rigurosa actitud fenomenológica de Husserl.

Pero no se trata ahora de presentar, con el mayor relieve posible, el aspecto ético de esta cuestión, sin duda alguna de extraordinaria importancia. Lo que ahora nos proponemos destacar es la razón por la cual el filósofo se ve constreñido, en los momentos de auténtica formulación de la imposibilidad cognoscitiva en que parece consistir la filosofía, a la adopción de una actitud negadora de todo contenido, a retraerse hasta la nihilidad más absoluta posible y buscar en ella el punto de partida, vale decir el fundamento, de la filosofía. Diríamos que una poderosa intuición guía el ánimo del filósofo en momentos de tanta importancia para el destino de su empresa como sucede en los respectivos casos de Sócrates, Descartes y Husserl, haciéndoles prescindir de toda posible concesión a lo dado, a toda Gegenstandstheorie, para buscar intrépidamente en el mar infinito de ese vacío que es el punto de partida puro y simple, desprovisto de todo presupuesto.

Y volvemos aquí, por consecuencia de lo inmediatamente dicho, a una cuestión formulada en este trabajo, es decir, a la diferencia que sí es posible establecer entre los grandes radicalizantes de la filosofía -principalmente Sócrates, Descartes y Husserl- y los restantes filósofos, hayan sido o no creadores de sistemas, tal como sucede con Platón, Aristóteles, Santo Tomás, Kant, Hegel, etc. Los radicalizantes -empleo la palabra con toda deliberaciónno creen en ninguna forma de realidad para la filosofía. Sócrates, como es sabido, desconfía de la investigación física y -según nos dice Xenofonte- le llenaba de asombro que los hombres no llegasen a comprender la imposibilidad en que se encuentran para resolver los enigmas que la realidad exterior les plantea. Pero es que tampoco, en lo que atañe a la realidad interior, jamás encontramos en Sócrates una afirmación que nos deje convencidos de que, al menos, creía en esto o aquello. Por eso los diálogos llamados "socráticos", en

Sócrates, reconozca que, en relación con la Sabiduria, la suya nada vale?" Platón, Apología, $9,23 b$. 
los cuales interviene Sócrates decisivamente, carecen de toda posible conclusión: por el contrario, en ellos vemos que la discusión, no importa cuán dilatada haya sido, termina con una declaración de expresa ignorancia, de impotencia para saber lo que ha sido el objeto de la discusión. Y lo decisivo a este respecto es que las cosas puestas en serio entredicho por Sócrates continúan en ese estado, a pesar de los siglos ya transcurridos, lo que demuestra que supo calar hasta las más insondables profundidades y advertir que el saber que busca la filosofía no es, pudiera decirse, de contenido, sino actitudinal, y en esto reside el inmenso significado del "sólo sé que nada sé" socrático, tan trivializado por demás en los manuales de filosofía. Pero con él ha puesto Sócrates la piedra angular de la verdadera filosofía, de la que implica su esencia como tal en la dramatis personae del sujeto filosofante. A partir de la lección socrática, todo aquel para quien la filosofía sea algo más que una logomaquia deberá convencerse previamente de que filosofar es partir de la más radical nihilidad y disponerse, no importa cuán largo sea el trayecto y las tentaciones que le salgan al paso, a no perder el camino por causa del paisaje, o sea que la filosofía puede proporcionarnos innumerables elementos con los cuales urdir toda la estofa de una realidad que nos satisfaga, pero, así y todo, esa urdimbre será siempre algo puesto por nosotros, pues mientras más se desmesure y complique, tanto más estará ella desviándonos de la realidad a que aspira la filosofía; mientras mayor vaya siendo el caudal de que disfrute, tanto menor irá resutando la verdad de ese caudal. Porque en definitiva $-\mathrm{y}$ éste es el mérito inmenso de Sócrates- el filósofo nunca puede estar satisfecho de "su" verdad. Hacerlo equivale a ocultarse en el amasijo de lo que ha elaborado con el propósito nada filosófico de reposar cómodamente en un conjunto de suposiciones. Y la filosofía, cuando se le toma en serio, no puede ser ni comodidad ni seguridad.

De esto último se desprende fácilmente la explicación de por qué la filosofía consiste en un constante replanteo de las mismas cuestiones fundamentales. Todo aquel que tenga suficiente capacidad para verlo, advertirá cómo el quehacer filosófico consiste en la revisión de los supuestos sobre los cuales han venido trabajando otros filósofos. Pero esta revisión puede, al menos, ser llevada a cabo o bien en forma radicalísima, tal como acontece con Sócrates, Descartes y Husserl, o bien puede ser que se le acometa sin la exigencia de un riguroso recomienzo. Pero, en cualquiera de los dos casos, filosofar es siempre revisar y replantear nuevamente, como si jamás lo hubiese sido, determinadas cuestiones que interesan al filósofo.

Pero la diferencia que acabamos de apuntar entre la radicalidad absoluta y la radicalidad relativa en cuanto al modus operandi del filósofo, determina a su vez el grado de credibilidad que el filósofo concede a la realidad y, por consiguiente, al saber que es posible derivar de dicha realidad. Cuando el sujeto filosofante opera como es posible observar que ocurre en Santo Tomás, Leibniz 
- Hegel, es decir, que parte del conjunto de supuestos que constituyen la problemática de su tiempo, y elabora un sistema de la realidad que consiste primordialmente en organizar y reestructurar lo ya dado, sin que esto impida a veces una asombrosa originalidad, la radicalidad es relativa. En esta misma situación se encuentra Kant, pues ya sabemos que no parte de ninguna situación radicalmente nueva, es decir, de un recomienzo a outrance, sino que, mejor, lleva a cabo una síntesis reorganizativa de supuestos dados ya en el pensamiento de su época, aun cuando realice modificaciones como la implicada en la trascendentalidad ${ }^{3}$ de su sistema. Mientras que en Sócrates, Descartes y Husserl nos encontramos en presencia de la radicalidad absoluta. Descartes - ¿habrá que decirlo? - entiende que es preciso acometer en serio la empresa de poner a un lado todo aquello en que se ha estado creyendo, y empezar de

3 Es claro que Kant introduce modificaciones tan decisivas en el proceso de investigación de la realidad que debe ser inalienable para la filosofía, como es la de su idea de la trascendentalidad, no ya sólo y en el comienzo, del conocimiento, sino por implicación, y en definitiva, de la realidad misma como tal. A este respecto, nos dice: "Ich nenne alle Erkenntniss transscendental, ảie sich nicht sowohl mit Gegenständen, sondern mit unserer Erkenntnissart von Gegenständen, sofern diese a priori möglich sein soll, überhaupt beschäftig. Ein System solcher Begriff würde Transscendentalphilosophie heissen." ("Llamo trascendental todo conocimiento que en general se ocupe, no de los objetos, sino de la manera que tenemos de conocerlos, en tanto que sea posible a priori. Un sistema de tales conceptos se llamaría Filosofía trascendental." E. Kant, Kritik der reinen Vernunft, Einleitung, VII, 25.) $Y$ en otra parte: "Und hier mache ich eine Anmerkung, die ihre Einfluss auf alle nachfolgenden Betrachtungen erstreckt, und die man wohl vor Augen haben muss, nämlich: dass nicht eine jede Erkenntriss a priori, sondern nur die, dadurch wir erkennen dass und wie gewisse Vorstellungen (Anschauungen oder Begriffe) lediglich a priori angewandt werden oder möglich sind, transscendental (d. i. die Möglichkeit der Erkenntnis oder den Gebrauch derselben a priori betreffend) heissen müsse. Daher ist weder der Raum noch irgend eine geometrische Bestinmung desselben a priori eine transscencientale Vor-Stellung; sondern nur die Erkenntniss, dass diese Vorstellungen gar nicht Empirischen Ursprung seien, und die Möglichkeit, wie sie sich gleichwohl a priori auf Gegenstände der Ehrfahrung beziehen könne, kan transscendental heissen. Imgleichen wïrde der Gebrauch des Raumes von Gegenständen überhaupt auch transscendental sein; aber ist er lediglich auf Gegenstände der Sinne eingeschränkt so heisst er empirisch. Der Unterschied des Transscendentalen und Empirischen gehört also nur zur Kritik der Erkenntnisse und betrift nicht die Beziehung derselben auf ihren Gegenständ." ("Debo hacer aquí una observación que tiene mucha importancia para lo que sigue y que es preciso no olvidar un instante. La palabra trascendental no conviene a todo conocimiento a priori, sino sólo a aquel mediante el cual conocemos que ciertas representaciones -intuiciones o conceptos- no son aplicados o posibles más que a priori y cómo lo son - pues esta palabra designa la posibilidad del conocimiento o de su uso a priori-. De esta suerte, no son representaciones trascendentales el espacio ni cualquier determinación geométrica a priori del espacio, y sólo puede tener el nombre de trascendental el conocimiento del origen no empírico de esas representaciones y de la manera con que pueden referirse a priori a objetos de la experiencia. Aś, también, será trascendental la aplicación del espació a los objetos en general [el subrayado es mío. Hay en esto último, mutatis mutandis, un desplazamiento de la idea de trascendentalidad a la posible realidad filosófica], y empírica cuando se limitara únicamente a los objetos de los sentidos. La diferencia de lo trascendental y lo empírico pertenece, pues, tan sólo a la crítica de los conocimientos y en nada respecta a la relación de esos conocimientos con sus objetos." E. Kant, op. cit., Die transscendentalen Logik, Einleitung, II, 80.) 
nuevo, desde los fundamentos, si se quiere establecer algo firme $y$ constante en las ciencias. ${ }^{4}$ Por su parte, Husserl, como es sabido, acoge gozosamente el criterio cartesiano, y en cuanto a él se refiere estrictamente como punto de partida del filosofar, lo suscribe sin reservas. "La filosofía - la sabiduría- es una incumbencia totalmente personal del sujeto filosofante. Debe ir fraguándose como su sabiduría, como aquel su saber tendiente a universalizarse que él adquiere por sí mismo, de que él puede hacerse responsable desde un principio y en cada paso, partiendo de aquella su evidencia absoluta." 5 Tendamos ahora una doble curva, que de Husserl vaya a parar, primero, a Descartes, y luego de éste a Sócrates: ¿no es cierto que en los tres alcanzamos a ver perfectamente la actitud del sujeto filosofante, para quien la filosofía ha de partir inevitable y necesariamente de sí mismo, que en el saber del no saber, no sólo inicialmente, como se ha pretendido que sucede con Sócrates, sino como conditio sine qua non inexorable del filosofar, reside la posibilidad misma de esa imposibilidad cognoscitiva que es la filosofía? Casi que estamos tentados a decir que ese saber del no saber es la toma de conciencia del no saber del saber, que cuando se hace lúcido, perfectamente claro, transparenta esa última y decisiva verdad en que parece consistir la filosofía: la comprobación efectiva de que, en última instancia, no podemos saber nada. Que al hombre le es dable ver para prever, como quería Comte, pero que esa visión no puede consistir más que en el acopio de datos y sus correspondientes relativas significaciones con la finalidad de tenernos en el mundo, una especie de Wissenschaft als Ob. La sabiduría que puede proporcionar la filosofía no puede ser ningún conocimiento, sino la lucidez por la cual advertimos la virtualidad de toda manifestación de la realidad. Recomenzar, como lo han querido algunos filósofos, es la mejor prueba efectiva de esa lucidez que, por otra parte, no se manifiesta del mismo modo en todo sujeto filosofante. ${ }^{\circ}$

4 "Animadverti jam ante aliquot annos quam multa, ineuente aetate, falsa pro veris admiserim, \& quam dubia sint quaecunque istis postea superextruxi, ac proinde funditus omnia semel in vita esse evertenda, atque a primis funảamentis denuo inchoandum, si quid aliquando firmum \& mansurum cupiam in scientis stabilire..." ("Hace ya mucho tiempo que me he dado cuenta de que, desde mi niñez, he admitido como verdaderas una porción de opiniones falsas, y que todo lo que después he ido edificando sobre tan endebles principios no puede ser sino muy dudoso e incierto; desde entonces he juzgado que era preciso seriamente acometer, una vez en mi vida, la empresa de deshacerme de todas las opiniones a que había dado crédito, y empezar de nuevo, desde los fundamentos, si quería establecer algo firme y constante en las ciencias." R. Descartes, Meditationes de prima philosophia, I, ab initio.) pág. 5 .

5 E. Husserl, Meditaciones cartesianas, trad. de J. Gaos, El Colegio de México, 1942;

6 "Uberlegungen darïber, wie sich das überall noch metaphysische und nur metaphysische Vorstellen in Wirksamer und nützlicher Weise zur unmittelbaren Aktion im täglichen und öffentlichen Leben bringen lasse, schweifen im Leeren. Denn je denkender das Denken wird, je entsprechender es sich sud dem Bezug des Seins zu ihm vollzieth; um so reiner steht das Denken von selbst schon in dem einem ihm allein gemässen Handeln." ("La reflexión sobre la vía que el pensamiento más universal y exclusivamente metafísico debería 
Tal parece ser la condición del sujeto filosofante en el destino que le corresponde a lá filosofía, pues mientras en el resto de los saberes cabe siempre un distanciamiento entre el que hace una ciencia y la ciencia misma, en lo que respecta a la filosofía es imposible realizar esta separación, ni siquiera con fines metodológicos. Por otra parte, como ya se ha dicho, la deliberación del sujeto respecto de la filosofía no la podemos hallar en la ciencia, pues en tanto que ésta se encuentra, de algún modo, en todas partes, circundando al hombre que con ella trabaja, al punto de que casi pudiera decirse que mientras la ciencia es una respuesta a ciertos estímulos que la realidad provoca en el hombre, la filosofía es pura invención humana, es morbosidad del espíritu, que lleva a éste a sospechar lo que en forma alguna le resulta advertible, ni tampoco se le insinúa bajo ningún aspecto. Eso que Sócrates llamaba, con el risueño aire de quien apenas dice nada, su demonio inspirador. ${ }^{\top}$

Es preciso, sin embargo, regresar a la pregunta que caracteriza de modo inequívoco al sujeto filosofante, de modo especial a aquel cuya radicalidad implica un riguroso recomienzo. ¿Por qué es preciso volver al punto de partida? Y, admitido que deba ser así, ¿cuál puede ser ese punto de partida? Y, todavía más, ¿por qué ese punto de partida?

No creo que haya otro quehacer cognoscitivo, excepción hecha del filosófico, donde resulte imprescindible regresar al punto de partida. En ninguna ciencia es posible encontrar, a lo largo de toda su trayectoria hasta el presente, casos como los de Sócrates, Descartes y Husserl. En ninguna de ellas cabría semejante demolición, tal derrumbe de todo supuesto hasta entonces admitido, para edificar completamente de nuevo los cimientos sobre los cuales deberá comenzar a erguirse otra vez la estructura filosófica. Y así como no tiene sentido realizar esa demolición en el sector de ciencia alguna, porque todas ellas se fundamentan y justifican en la continuidad histórico-temática que respectivamente las constituye, la filosofía, en cambio, sí requiere de esa disolución, la auslössung que para Husserl es imprescindible si de veras se quiere llegar a la constitución de una filosofía genuina y por lo mismo válida. Peculiarísima condición esta de un periódico recomienzo, sin el cual no hay filosofía

seguir eficaz y útilmente para ejercer una acción inmediata en la vida cotidiana y pública se convertiría entonces en algo caduco. Según el pensamiento se hace más pensante, haciéndose más puro a partir de su relación con el ser, y más determinado, se encuentra empeñado consigo mismo en la única acción, la única que le es adecuada." M. Heidegger, Was ist Metaphysik?, Einleitung, Der Rückgang in den Grund der Metaphysik, S. 12.)

7 "Quizá resulte extraño que aconseje privadamente tales cosas, yendo de uno a otro, con gran diligencia, y que, no obstante, al subir aquí no me atreva, en nuestra Asamblea, a aconsejar con vosotros públicamente a la Ciudad. La causa de esto es, según me lo habéis oído referir en diferentes ocasiones, y en diversas formas, que me sobreviene algo a la vez

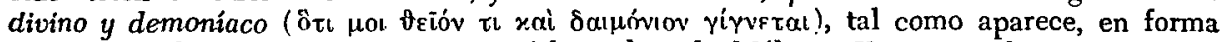
de farsa, en la acusación que contra mí ha redactado Méletos. Y esto es algo que empezó a sucederme desde pequeño, en forma de cierta voz ( $\varphi \omega v \eta ́$ $\tau ا \zeta$ ) que, al sobrevenirme, mo convence para que no haga lo que estoy a punto de hacer, pero que jamás me persuade de que haga algo determinado." Platón, Apología, 3lc-d. (El subrayado es mío.) 
posible; pero que si intentamos aplicarla al resto de los saberes, en lugar del resultado a que la filosofía nos tiene acostumbrados, presenciaríamos una con. clusión definitiva de tales saberes. La filosofía, por consiguente, requiere, por lo visto, un recomienzo, pero no al modo de la consabida Aufhebung, o sea una parcial superación canceladora de etapas previas, que esto sí es posible para la ciencia; sino, por el contrario, empezar totalmente de nuevo, como si jamás se hubiese hecho filosofía.

Quiere decir esto último que el quehacer filosófico se aplica a un cuerpo - permítasenos llamarlo así- cuya naturaleza es de tal modo sui generis, que es singular y única. Naturaleza que exige ser destruída tan periódica y metódicamente como lo exige asimismo su propia construcción. Imaginemos una ciencia en la cual hubiera que prescindir de todo lo hecho hasta un instante dado, verbigracia, la matemática, la física o la psicología. El único resultado obtenible sería el de no poder integrar jamás eso que podemos denominar matemática, o física, o psicología, pues quien tal hiciera estaría obligado a permanecer sine die en el puro comienzo. Pero, yendo ahora al otro extremo de la cuestión, imaginemos la filosofía sin las radicales interrupciones a que ha sido sometida en ciertos momentos de su historia, sin contar las innumerables reconsideraciones de segundo o tercer grado - lo que han hecho Kant, Leibniz, Duns Scotus, Santo Tomás, Condillac, Vico, etc. El resultado sería algo tan distinto de la filosofía, que en verdad ésta no aparecería por ninguna parte, perdida en la frondosidad inabarcable de toda suerte de formulaciones correspondientes a todas las manifestaciones del saber en general. Y con esto hemos llegado a las otras dos cuestiones que completan la que venimos desarrollando, a saber: ¿cuál puede ser ese punto de partida? Y, ¿por qué ese punto de partida? -en el supuesto de que. acabemos dando con él.

\section{El problema del "punto de partida"}

La filosofía es sabiduría, siempre que yo, al menos en el comienzo, en cuanto actúo como el sujeto filosofante, me disponga a no partir de nada que no sea mi pura y nuda interioridad. Pues, ¿qué puede decirme lo exterior, entendido por esto todo aquello que no es estrictamente la interioridad de mi propia subjetividad? Para Sócrates, la sabiduría no es cosa de más o menos conocimiento, sino de radical seguridad de que no es posible saber nada efectivamente, vale decir decisivamente. Pero no el saber de un no saber que puedé luego trocarse en el saber del saber lo que se ignoraba. No. Pues si la cosa fuese así, apenas tendría importancia la filosofía, y vendría a quedar relegada a la condición de mera provincia del orbe del conocimiento en general. Para que sea esa curiosidad que muerde afanosa e incansable en el espíritu del hombre, no ya principalmente sobre el qué y el porqué de todo, sino sobre lo que cabe llamar el porqué de los porqués, esos tres pies del gato volteria- 
no, es preciso que la fisolofía no tenga nada, que sea desolada menesterosidad, y que sepa, además, que debe estar siempre resuelta a serlo por modo irrevocable.

Esta posición, que Sócrates ejemplariza, ha sido siempre paradigmática en la filosofía, se le haya o no buscado por quien filosofa, si es que lo ha hecho de veras. En el fondo, es lo que intenta sostener Parménides al establecer la identidad del ser y el pensar. Pues, en el comienzo como en el final, todo es nada y uno es todo, ya que ese saber de una totalidad -donde lo individual, vale de lo que posee accidentes, lo que sufre cambios, lo que nace y muere, no es conocible por la razón-, si bien lo es todo, justamente por esto mismo es que, a la vez, no es nada, en el sentido de esto o aquello, es decir, lo individual. Como ocurre igualmente en la posición agustiniana del in interiori

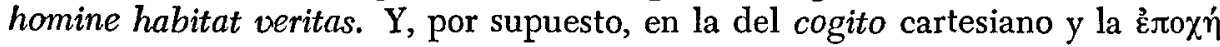
de Husserl. El punto de partida es, pues, el mismo en todos los casos, a saber: la imposibilidad de admitir como válido lo exterior circundante, lo que nos rodea y predetermina, tanto en el orden del conocimiento cuanto en el de la acción.

Pero el sujeto filosofante abandona casi de inmediato esta difícil e insostenible posición, para buscar apoyo en algo que ya no es la pura y nuda interioridad, y aquí reside justamente el peligro que acecha en todo instante a la filosofía, aun cuando deba ser dicho que este peligro puede ser, tal vez, una condición insoslayable para la filosofía. Y si fuera así, nos permitiría comprender por qué el filósofo está obligado a ese continuo tejer y destejer, a ese renunciamiento periódico, sin el cual dejaría de ser lo que es. La pregunta, ingenua como todas, pero no por ello menos indispensable, es ahora ésta: ¿Por qué ha de retraerse el filósofo hasta la más rigurosa soledad e indigencia del saber, si luego la abandona para entregarse con fruición al mundo de las plenitudes de la realidad? ¿Es, acaso, que no puede hacer otra cosa? Al admitir que, efectivamente, debe ser así, sentimos que un estremecimiento nos sacude, pues la propia historia de la filosofía enseña -iy de qué admirable manera!- que la única porción válida, strictu sensu, en el filosofar es precisamente esa que constituye el método, la actitud inicial del sujeto filosofante. Probemos a suprimir la ironía en el diálogo socrático, y lo demás vale bien poco, pues apenas si opera como "fermosa cobertura". Sócrates está, por consiguiente, de cuerpo entero, decisivo y eterno, en la majestad de su irónica mayeusis. Como lo decisivo en Descartes es ese breve proceso - breve si lo comparamos con el resto de su voluminosa obra- por el cual llegamos a su genial formulación del cogito, ergo sum. Y lo mismo acontece en Husserl, cuya obra, en su totalidad, gira, a veces con maniática obsesión, en torno de la reducción fenomenológica. Lo demás, pese a la enorme importancia que reviste, es siempre subsidiario de dicha reducción.

El punto de partida aparece, entonces, como el propio sujeto filosofante, 
o sea que, en principio, la realidad exterior, si hemos de tomar en cuenta a los grandes filósofos, apenas significa algo. Por otra parte, vemos que la actitud contenida o implicada en ese punto de partida sigue siendo lo verdaderamente válido en la elaboración filosófica de que se trate. Y, entre ambos, se mueve esa realidad de la que el filosofo comienza por evadirse y a la que regresa una vez completado el proceso que engendra el punto de partida. Y en esto se aloja la paradoja aparente de la filosofía, la cual, vista en cierta perspectiva, es real y no aparente, pues la esencia de la realidad consiste en ser toda ella paradójica, y la filosofía no tiene por qué constituir una excepción.

Hemos dicho que el sujeto filosofante comienza retrayéndose por modo riguroso de todo lo que no sea su propia subjetividad, absolutamente libre de toda contaminación con la realidad. Ésta es, al menos, su pretensión. Pero el sujeto filosofante no está solo, sino que, por el contrario, el retraimiento a que se somete voluntario es consecuencia de una realidad que le circunda, de la cual forma parte indisoluble y a la cual debe acatamiento, lo quiera o no. Si trata de evadirse de esa realidad es porque puede advertir que la misma no satisface las exigencias de una certeza, vale decir de una credibilidad, que fundamenta el saber filosófico, o mejor quizás esa sabiduría a que aspira el filósofo. Su exigencia de una certeza absoluta implica la negación de toda forma de realidad, porque esa sabiduría a que el filósofo aspira no se puede satisfacer con medianías de ningún género; pero, a la vez, la sabiduría es comprobación de la imposibilidad de arribar a una plena certidumbre en cuanto se refiere a la realidad. Si esto es así, ¿jpor qué decide el filósofo regresar a la realidad?

La respuesta apenas exige esfuerzo. El sujeto filosofante regresa a la realidad porque su fuga de ella es más bien virtual que real. En rigor de verdad, jamás dicho sujeto podría abandonar de veras la realidad a la cual está indisolublemente unido. Si, al filosofar -nótese el subrayado- se retrae de la realidad, lo hace porque advierte la irremediable relatividad de todo conocimiento y, por lo mismo, la concomitante de su irremediable certidumbre relativa. Pero como, al menos para el filósofo, deben ser cuestiones del todo distintas entre sí la relatividad de la certidumbre cognoscitiva en general y la absolutidad de la exigencia de una veracidad plena, el filósofo ha de proceder, en cuanto actitud metódica, es decir, puesto que se trata de una actitud personal, como si la fuga o el retraimiento aludidos fuesen "realmente" posibles, y no un modus operandi. Y esto nos lleva como de la mano al planteo de la situación esencial en el filosofar, es decir, la que consiste en la contradicción entre el retraimiento que implica la exigencia de veracidad absoluta y la elaboración posterior que lleva a cabo el filósofo, a base de los elementos que esa realidad, de la cual comienza por ausentarse, le proporciona. Y a esto se debe que al leer la obra de un gran filósofo resintamos siempre esa desmesura entre la parte que corresponde al proceso de retraimiento y exigencia de radi- 
calidad y la que corresponde al resto de su obra. Se advierte que la mayor parte de su construcción es fácilmente desechable, o al menos no exige que la tengamos en cuenta del mismo modo que la primera. Pero, hemos dicho, el filósofo no puede escapar decisivamente a la realidad, por lo que el filosofar es, visto de cierto modo, un estar y no estar a la vez en la realidad. No en balde Aristófanes lleva su mezquino odio sofístico contra Sócrates al extremo de situarlo entre las nubes. El juego interactivo entre el solipsismo (implícito o explícito) del filósofo y esa realidad a la cual regresa como en una especie de confiteor de sí mismo, caracteriza decisivamente al filósofo.

\section{El problema de la "realidad" de la filosofía}

Nos hallamos justamente ahora en el terreno de todas las discordias filosóficas, es decir, aquel en el cual es preciso saber a qué atenerse, si se aspira a filosofar con efectividad. Pues de nada vale que se esfuerce el sujeto filosofante por realizar un avance en tal o cual aspecto de la filosofía, mientras no sepa cuál es la naturaleza de esa realidad en la cual aquélla debe moverse. Pero ¿acaso ha sabido alguien efectivamente qué es la realidad filosófica?

La cuestión, sin embargo, sigue siendo tan previa como en el origen mismo de la filosofía. Porque mientras los restantes tipos de saber, digamos, con las palabras de Husserl, las restantes ciencias, han ido determinando consecutivamente sus respectivos campos de actividad, es decir, la naturaleza de su respectiva realidad, ${ }^{8}$ de manera que ya hoy podemos afirmar con aceptable precisión cuál es el campo de acción y la naturaleza sobre la cual opera la matemática, o la física, o la química, o la biología, etc., todavía seguimos, como en el comienzo, sin saber a qué atribuir la realidad de la filosofía. ¿Será, acaso, que no la tiene? Pero, entonces, ¿y los filósofos? ¿¿ la filosofía contenida en sistemas y tratados? ¿Es que se puede llegar, así sin más, a la conclusión de que la filosofía carece de entraña real?

Partamos, pues, de una consideración que nadie se atreverá a rechazar, como es la de que, en efecto, existe la filosofía y existen los filósofos. Y que éstos han llevado a cabo siempre un género de actividad sui generis... que sin posible engaño es menester reconocer como la filosofía. Conviene hacer esta aclaración para no recaer en las manualescas disquisiciones de si la obra de tal o cual filósofo es o no es filosofía, o si, por lo menos, está fuertemente saturada de ingredientes no filosóficos. Creo que nadie podría negar en serio que Tales, Platón, San Agustín, Bacon, Descartes, Hume, Kant, Hegel, Bergson o Heidegger -para citar sólo algunos nombres- son filósofos, aun cuando en sus respectivas elaboraciones sea posible discernir más de un ingrediente propio de alguna ciencia. Así, no hace al caso que Descartes esté fuertemente

8 Hasta un límite aceptable, pues considerar la cuestión in extremis sería tanto como trasladarse al interior de la cuestión que aquí venimos analizando. 
influído por la matemática, o que la biología se muestre con insistencia en las formulaciones de Bergson. De todos modos, son filósofos; pero ¿por qué? Ese por qué sólo puede disolverse en una respuesta satisfactoria siempre que logremos ponernos de acuerdo acerca de la realidad propiamente filosófica.

Pero la filosofía, no debemos olvidarlo, es una actividad que lleva a cabo un ser histórico, el hombre, siempre dentro de una situación igualmente histórica. Lo cual quiere decir que el hombre, en cuanto sujeto histórico, viene haciendo filosofía, como ha venido haciendo otras muchas cosas, en virtud de sus peculiares capacidades, una de las cuales es, sin duda, la de filosofar. Y al filosofar, el hombre ha tenido que actuar, históricamente, conforme con las circunstancias prevalecientes en cada situación que le ha tocado vivir. Así, la situación que le corresponde a Sócrates en la Atenas del siglo v no puede ser la misma que la de San Agustín en ese otro siglo $\mathrm{v}$ que sirve de frontera a dos épocas; como no es la misma la situación dentro de la cual Descartes filosofa -el siglo en que se afianzan la matemática y la física modernas- que la presente en la cual surge, dentro de la grave crisis de esa misma ciencia moderna, una filosofía como la de Heidegger y Sartre, o el neopositivismo. Ahora bien, afirmar esto último ¿no equivale a decir, sin cortapisas, que la realidad de la filosofía es, en cierto sentido, cambiante sine die? Sí y no. Lo primero, porque si bien la realidad en la cual opera el filósofo es la misma realidad en general que predetermina su obra, de la cual extrae el filósofo los materiales para su especulación, dicha realidad, la estrictamente filosófica, no es sólo simple porción de esa realidąd en general, sino que está decisivamente condicionada por lo que en ella subtiende el sujeto filosofante. $Y$ esto es lo segundo, 0 sea que precisamente porque hay quien filosofa, alguien cuya subjetividad predetermina esa porción de la realidad en general a la cual le interesa aplicar sus especulaciones, es que la realidad que apareja el filosofar no es cambiante, sino siempre la misma. El modo peculiar, pues, con que el sujeto filosofante acoge esa realidad que le interesa primordialmente, la forma sui generis de concebirla, es algo arquetípico y a la vez inmutable. Por esto es que Tales, visto en la dimensión más amplia del filosofar, es tan filósofo como Sócrates o Kant. En cuanto nos referimos a su filosofía, estrictamente, o mejor a su actitud ante la realidad, Tales nos aparece como genuino filósofo. Desde el momento en que pregunta qué es la realidad, ingresa con todos sus derechos en el orbe de la filosofía.

Esta actitud inicial del sujeto filosofante por la cual la realidad se trueca en una realidad específica es la que determina que exista eso que podemos llamar realidad filosófica. Porque, en definitiva, como lo ha intentado demostrar Husserl, la actitud filosófica es un estadio o fase en el proceso del vivir, el más elevado de todos, pero sin duda uno de ellos. Recuérdese que, según el filósofo de Friburgo, la vida humana comienza por una "instalación natural" (natürliche Einstellung), que tiende a subdividir la totalidad de la reali- 
dad en cuatro sectores, a saber: el mundo de las cosas (Sachenwelt), el de los valores (Wertewelt), el de los bienes (Gütewelt) y el de la práctica (Praktischewelt). En esta sectorización se mueve el hombre y en ella actúa en la forma más natural posible, como propia de quien se halla inmerso en un mundo para cuya participación no ha sido consultado previamente. Pero el hombre puede, sin salirse efectivamente del mundo natural, "desconectarse" de él para ingresar en la esfera de otro mundo, pongamos por caso el matemático, y entonces, más que de una instalación, se trata de una actitud por la cual puede el hombre, no sólo reflexionar acerca de los objetos de ese mundo cabalmente, ya que se encuentra desconectado del mundo natural, sino que, además, está en ellos mientras dure la actitud por la cual el hombre se ha trasladado a ese otro mundo; a diferencia de lo que ocurre con el mundo natural, del cual jamás podemos evadirnos por la puerta de la reflexión, en la actitud que implica el tránsito al mundo matemático, o al lógico, etc. $Y$ ya aquí encontramos una primera distinción entre la realidad común a toda manifestación del saber y estas manifestaciones como tales. Pero no, por supuesto, entre éstas y la filosofía. Para hallar una radical será preciso que avancemos, siempre de la mano de Husserl, hacia etapas todavía más distantes de la instalación natural.

Pero ya la actitud por la cual es posible desentenderse del mundo de la instalación natural e ingresar en el mundo de los eídos permite descubrir algo que ha sido a lo largo de los siglos el motivo de tremendas confusiones, cual es la distinción entre las respectivas naturalezas de lo eidético y lo universal. El número 2, la circunferencia, dice Husserl, son Ello 0, o sea un tipo o manifestación de la realidad que no admite la subordinación del género o la especie con el individuo. Así, sucede que cuando se dice, verbigracia, "tres ruedas", no se trata de casos que estén comprendidos en la extensión de los conceptos tres y circunferencia, sino que se trata de casos casuales en los cuales se han realizado esos conceptos. Mientras que conceptos como los de hombre, mesa, ave, $s_{j}$ son universales, puesto que hacen referencia global a todos los individuos de la misma especie o género, de taI manera, que mientras son los individuos lo primario, el punto de partida, los universales son como tales algo abstracto, vago, que adquiere concreción y fuerza significativa en los individuos a los cuales se refieren.

$\mathrm{Y}$ esta distinción es sutilísima, e implica, aun cuando no lo diga taxativamente Husserl, una distinción entre los universos de objetos correspondientes a los saberes todos, excepto el filosófico, y el que pertenece a la filosofía. Pues toda ciencia, en su sentido más amplio y aceptado, se mueve en esa relación subordinante de lo individual y lo universal, mientras que la filosofía, si hemos de hallar su realidad inalienable, no puede descansar aquí, aun cuando deba transitar por este terreno.

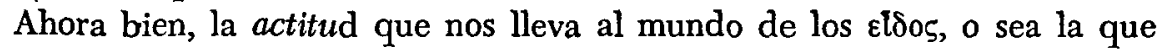
nos saca del mundo de la instalación natural, implica diversas modalidades 
(Modalisierung) como son, por ejemplo: afirmar, negar, dudar, querer, obrar, etcétera. Pero estas modalidades son posibles porque ellas constituyen lo que llama Husserl la libertad omnimoda (vollkommene Freiheit). Dichas modalidades, en las cuales se individualiza y personifica la actitud (el "ponerse a"), son las responsables de que las cosas aparezcan como en sí; no que las cosas no existan, con independencia de la actitud del sujeto, pues ya se ha dicho que están ahi, sin más, en el mundo de la instalación natural, sino que se me dan, al ponerme a ellas, como afirmadas, o negadas, o dudadas, o queridas, etc. Pero esto último lleva a pensar si acaso es posible que el sujeto no se ponga a nada. Pues bien, es posible, ya que si no fuera así entonces toda la realidad nos sería necesaria, o sea que no podríamos prescindir de ella. Y esto empata aquí con lo ya dicho en este trabajo acerca de que la actitud del sujeto filosofante determina el tipo de realidad específicamente filosófica. La posibilidad de una desconección con la realidad implica, por una parte, que la realidad de las cosas depende de esa actitud por la cual el sujeto se pone a afirmarlas; $y$, por otra, que ese mismo ponerse a implica una rigurosísima subjetividad. Pero el propio Husserl se encarga de salirle al paso a esta grave observación, que compromete decisivamente a toda la realidad, para decirnos que es posible contraponer a la "tesis" opuesta del mundo, que es "casual", la "tesis" del Yo puro y de la vida de tal Yo, que es necesaria, porque, dice, "todas las cosas, aun las que están dándose en persona, pueden igualmente no existir; pero ninguna vivencia que esté dándose en persona puede no existir". 9 De este modo, no hay posible acto real si no se pone alguien a ponerlo, con lo que resulta que la realidad del acto depende de su posición. Para salvar el abismo inminente de una subjetividad radicalísima, Husserl expresa que: "la necesidad entitativa (Seinsnotwendigkeit) de cada una de las vivencias, actuales en un momento dado, no es únicamente pura necesidad esencial...; se trata de una necesidad de hecho, llamada así porque el hecho participa de una ley esencial... En la esencia misma y en cuanto tal de un Yo puro y en la de una vivencia en cuanto tal se funda la posibilidad ideal de una reflexión, que tiene el carácter esencial de una puesta evidente e ineliminable de realidad". ${ }^{10}$

9 Dice exactamente Husserl (Ideen, Halle, 1913; p. 86): “Der Thesis ảer Welt, die eine 'zufallige' ist, steht also gegenüber die Thesis meines reinen Ich und Ichlebens, die eine 'notwendige', schlechthin zweifellose ist. Alles leibhaft gagebene Dingliche kann auch nicht sein, kein leibhaft gegebenes Erlebnis kann auch nicht sein: das ist das Wesensgezetz, das diese Notwendigkeit und jene Züfalligkeit definiert." ("Frente a la tesis del mundo, que es una tesis 'casual', se alza, pues, la tesis de mi yo puro y de la vida de este yo, que es una tesis 'necesaria', absolutamente indubitable. Toda cosa dada en persona puede no existir; ninguna vivencia dada en persona puede no existir: tal es la ley esencial que define esta necesidad y aquella contingencia." El subrayado en el texto es mío.)

10 E. Husserl, op. cit., págs. 86-87: “Offenbar ist die Seinsnotwendigkeit des jeweiligen aktuellen Erlebnisses darum doch keine pure Wesensnotwendigkeit, $d . i$, keine rein eidetische Besonderung eines Wesensgesetzes; es ist die Notwendigkeit eines Faktums, die so heisst, weil ein Wesensgesetz am Faktum, und zwar hier an seinem Dasein als solchem, beteilig 
Estas últimas palabras permiten vislumbrar la idea que el filósofo Husserl tiene acerca de lo que puede ser la realidad filosófica, o sea la realidad sive philosophia, puesto que él actúa, en este caso, como sujeto filosofante. Porque, es ocioso decirlo, así no se le ocurre pensar ni al hombre vulgar ni tampoco al de ciencia, sino sola y exclusivamente al filósofo. Notemos, por lo pronto, que Husserl entiende que, en primer término, hay la posibilidad ideal de una reflexión, cuya esencial característica es, en segundo lugar, una puesta evidente y no eliminable de realidad; que, en tercer lugar, se basa en la simultánea esencia de un Yo puro y de una vivencia en cuanto tal. Pero ¿qué quiere dar a entender Husserl con la expresión "esencia misma y en cuanto tal de un Yo puro y en la de una vivencia en cuanto tal"? El entiende, con sobrada razón, que en la esencia a la vez general y abstracta del Yo y de la vivencia hay una posibilidad, pero no una realidad, pues la vivencia es, siempre e inevitablemente, vivencia de alguien y de algo (el pensar es siempre pensar de alguien en algo, etc.), de manera que cada vivencia realiza, pues, en forma individual y concreta (Dies- da), la esencia general y abstracta de vivencia. Ahora bien, ¿en qué consiste esa posibilidad de esta vivencia? La posibilidad consiste en una reflexión, es decir, que la conciencia de la vivencia, el poner el acto cogitativo como objeto de la reflexión, asegura la realidad de aquello que constituye el objeto de la vivencia. De este modo, a la realidad simple, que se muestra sin más en la instalación natural, sobreviene, tras el proceso de la reducción fenomenológica, tal como se le acaba de esbozar, la realidad puesta, o sea la realidad que se hace consciente.

Pero esta capacidad que posee la reflexión para conferir a las cosas su condición ontológica real implica, en última instancia, la siguiente contrapartida: ella puede, mejor sería decir que debe, eliminar de cada vivencia sometida a la reflexión -o lo que es lo mismo, puesta como real - hasta el más ligero vestigio del objeto correspondiente a dicha vivencia y al cual se encadenaba la vivencia por su intencionalidad, con lo cual convierte el objeto en simple y desnuda presencia, desprovista de toda capacidad afirmativa. De esta manera, llega el sujeto a la plenitud, si es posible decirlo así; de su capacidad de indiferencia frente a toda realidad; con lo cual se cumple nuestra afirmación de que la reducción fenomenológica no deja en momento alguno de ser el gozne sobre el que gira afanosa toda la realidad según Husserl la concibe. Queda, pues, toda objetividad siempre en entredicho, "entre paréntesis" (Einklammerung), de suerte que la realidad, que comenzó siendo real, concluye siendo, a lo sumo, eso que en la terminología del autor se denomina el noema.

Y, entonces, ¿qué? Es fácil advertir ahora cómo la realidad filosófica sigue presentando, aunque es claro que con las variantes de los tiempos, las dos

ist. Im Wesen eines reinen Ich ïberhaupt und eines Erlebnisses überhaupt gründet die Ideale Möglichkeit einer Reflexion, die den Wesenscharakter einer evident unaufheblichen Daseinsthesis hat." (Transcribo el párrafo completo.) 
notas peculiares que la caracterizan inequívocamente, a saber: en primer lugar, que es una realidad que depende de la subjetividad del sujeto filosofante, que es el terreno donde se asienta, de donde emerge y se muestra en cada caso; en segundo lugar, que esta realidad carece de toda precisión, es decir, que no es posible asignarle nota alguna que nos permita, en forma a la vez consciente y cómoda, determinar su modo de ser o consistencia. Porque esta realidad filosófica, que no es en definitiva sino el residuo final de ese sutil proceso de destilación por el cual ascendemos desde la realidad inmediata de la instalación natural - del mundo del hombre ingenuo- y a través de la realidad de todo otro saber -las ciencias- hasta la enrarecida atmósfera de la especulación filosófica, esta realidad, repetimos, es sólo presencia indetermina$d a$, paradójicamente, a fuerza de operar con la mayor precisión posible en las realidades que le preceden. La posibilidad real de la filosofía parece, pues, consistir en una imposibilidad radical que la engendra continuamente. Podemos pensarla, hacerla objeto de nuestra reflexión como pura presencia; pero en cuanto tratamos de complicarnos con ella, como sí pueden hacer con las suyas respectivas el hombre ingenuo y el de ciencia, se nos evapora. $\mathrm{Y}$, sin embargo, podemos -y debemos- seguir haciendo filosofía.

Porque la conclusión a que llega Husserl respecto de la realidad sobre la cual debe operar la filosofía (la realidad filosófica) no es sino la que acabamos de apuntar, es decir, la reducción fenomenológica como punto de partida, no hace, en la totalidad de su proceso, sino robustecerse a sí misma y afianzarse, en cierto sentido, como una autoconsecuencia, si es posible expresarse así; al punto de que, en su fase final, o sea cuando la realidad ya se nos da bajo la especie irreal y hasta vagarosa de lo noemático, la reducción es lo que viene a mostrarse como lo único subsistente. $\mathrm{Y}$ tanto lo es de este modo, exactamente, que por eso es posible designar el proceso íntegro de la reflexión, tal como funciona dentro de la reducción fenomenológica, como la conciencia de una conciencia... y así hasta el infinito. Esta virtualidad de la conciencia fenomenológica ha sido magistralmente advertida y señalada por Heidegger, cuando nos dice: "Fenomenología es la forma de acceder a lo que debe ser tema de la ontología y la forma demostrativa de determinarlo. La ontología sólo es posible como fenomenología. El concepto fenomenológico de fenómeno entiende por 'lo que se muestra' el ser de los entes, su sentido, sus modificaciones $y$ derivados. $\mathrm{Y}$ el mostrarse no es un mostrarse cualquiera, ni menos lo que se dice un 'aparecer'. El ser de los entes es lo que menos puede ser nunca nada 'tras de lo cual' esté aún algo 'que no aparezca'." 11 Y un poco más ade-

11 "Phänomenologie ist die Zugansart zu dem und die ausweisende Bestimmungs-Art dessen, was Thema der Ontologie werden soll. Ontologie ist nur als Phänomenologie möglich. Der phänomenologische Begriff von Phänomen meint als das Sichzeigende das Sein des Seienden, seinen Sinn, seine Modifikationen und Derivate. Und das Sichseigen ist kein beliebiges noch gar so etwas wie erscheinen. Das Sein des Seienden kann am wenigsten je 
lante, precisa y reafirma lo anterior al decir: "La dilucidación del primer concepto de la fenomenología indica cómo lo esencial de ésta no reside en ser real como 'dirección' filosófica. Por encima de la realidad sé encuentra la posibilidad. La comprensión de la fenomenología radica únicamente en tomarla como posibilidad." 12

Heidegger, por consiguiente, también ha visto claro en el problema de la realidad de la filosofía, que es como decir en el problema de su posibilidad real. Y sentenciosamente concluye que el camino de una continuidad sólo puede señalarlo la posibilidad, ya que todo esfuerzo por encontrarle su realidad a la filosofía concluye, por modo inevitable, en conclusiones a fortiori. $Y$ esto es lo que ha sucedido siempre en la historia de la filosofía, de donde su consecutivo anacronismo y la caducidad consiguiente para la mayoría, por no decir la totalidad, de sus formulaciones. Sin desdeñar los méritos de los descubrimientos colaterales a la reducción fenomenológica, se puede afirmar que ella constituye el descubrimiento más importante en la filosofía desde la aparición del cogito, ergo sum cartesiano, pues el noema, como la porción más destilada de la realidad a través de la reducción trascendental, difiere sólo gradual y no esencialmente de la certeza apodíctica de Cartesius. Pues el mayor afinamiento y precisión de la reducción fenomenológica respecto de la duda metódica, no prueban, en fin de cuentas, sino que la realidad de la filosofía, para Husserl como para Descartes, como hubo de entreverlo igualmente Sócrates -aunque no en la forma decantada que ofrece en los otros dos-, es y deberá ser siempre la misma, a saber: pura posibilidad. Parafraseando a Heidegger, diríamos que, en nuestro concepto, la comprensión de la filosofía sólo puede consistir en tomarla como posibilidad.

Humberto Piñera Llera

Universidad de La Habana

so etwas sein, 'dabinter' noch etwas steht, 'was erscheint'." M. Heidegger, Sein un Zeit, Neomarius Verlag Tübingen, 1949; págs. 35-36.

12 "Die Erläuterungen des Vorbegriffes der Phänomenologie zeigen an, dass ihr Wesentliches nicht darin liegt, als philosophische 'Richtung' wirklich zu sein. Hoher als die Wirklichkeit steht die Möglichkeit. Das Verständnis der Phänomenologie liegt einzig in Ergreifen ihrer als Möglichkeit." M. Heidegger, op. cit., p. 38. 